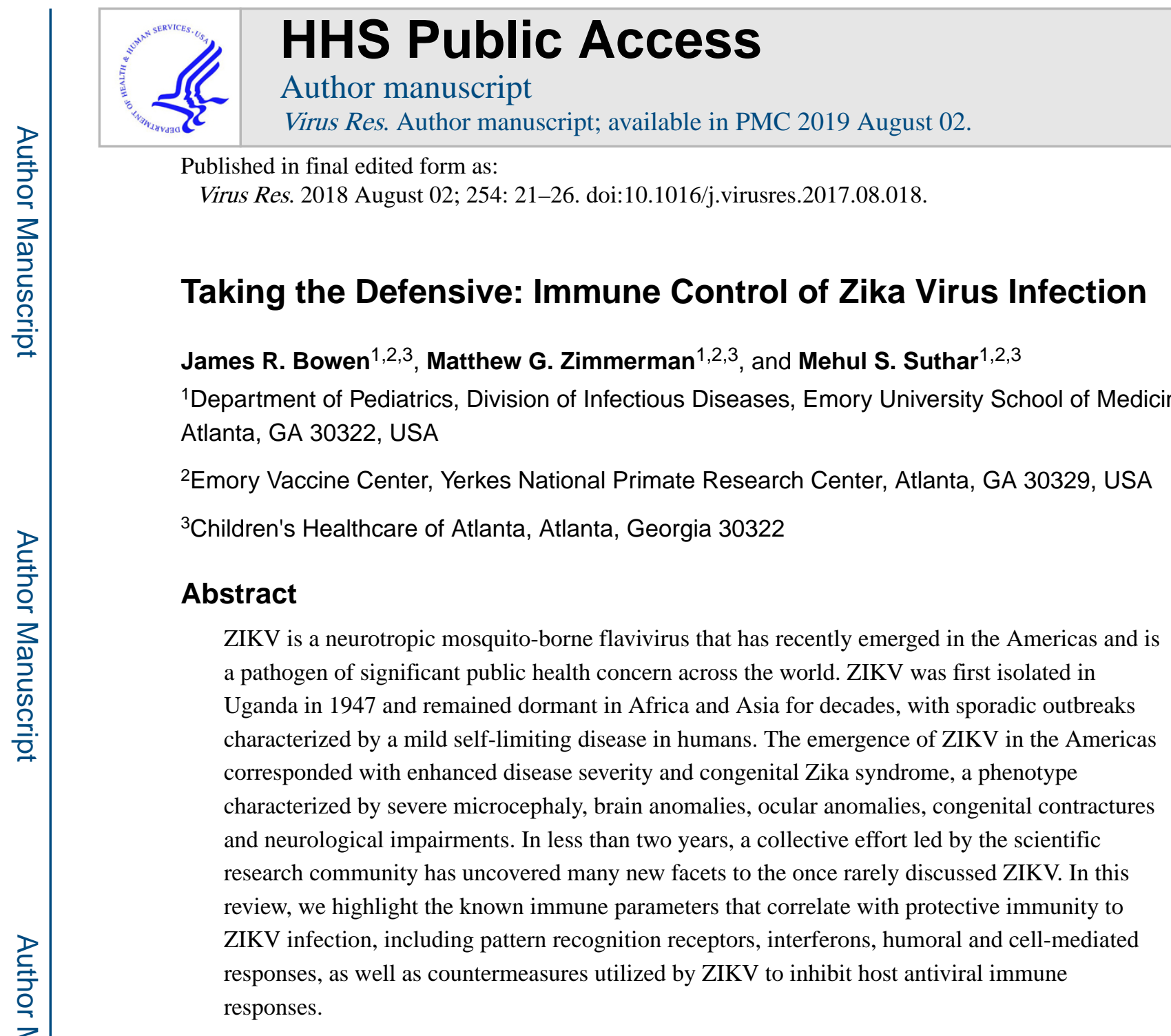

\title{
Keywords
}

Zika virus; type I interferon; RIG-I; MDA5; RIG-I signaling; Flavivirus; viral antagonism; innate immunity; JAK/STAT signaling; antibody; T cells

\section{Zika virus emergence}

Zika virus (ZIKV) is a neurotropic flavivirus that is the etiologic agent responsible for causing the recent epidemic of congenital Zika syndrome (CZS), a phenotype characterized by severe microcephaly, brain anomalies, ocular anomalies, congenital contractures and neurological impairment (Moore et al., 2017). ZIKV is predominately transmitted through

Correspondence to: Mehul S. Suthar.

Present mailing address: Yerkes National Research Center, 954 Gatewood Road; Office 2022, Atlanta, GA 30329, USA, Phone: (404) 727-3052 Fax: (404) 727-8199

The author declares no commercial or financial conflict of interest.

Publisher's Disclaimer: This is a PDF file of an unedited manuscript that has been accepted for publication. As a service to our customers we are providing this early version of the manuscript. The manuscript will undergo copyediting, typesetting, and review of the resulting proof before it is published in its final citable form. Please note that during the production process errors may be discovered which could affect the content, and all legal disclaimers that apply to the journal pertain. 
the bite of an infected mosquito, however, it has recently been demonstrated that ZIKV can also be transmitted in utero, through sexual contact and blood transfusion (Calvet et al., 2016). The ability of ZIKV to be vertically transmitted is a unique feature that has not been described for any other mosquito-borne flavivirus in humans. ZIKV is closely related to dengue virus (DENV) and members of the Japanese Encephalitis virus (JEV) serogroup strains, such as West Nile virus (WNV) (Weaver et al., 2016). While all known strains of ZIKV fall into a single serotype, genetic evidence suggests three distinct lineages: the East African, West African, and Asian lineages (Dowd et al., 2016; Haddow et al., 2012; Lanciotti et al., 2016). ZIKV was first isolated from an infected sentinel rhesus macaque in the Zika forest region of Uganda in 1947 (Dick et al., 1952) and remained dormant in Africa and Asia for decades, with sporadic outbreaks characterized by a mild self-limiting disease in humans (Weaver et al., 2016). Most recently, Asian lineage viruses have emerged as a global public health threat with widespread epidemics in Micronesia (2007), the Pacific Islands (2013-2014), and the ongoing epidemic in the Americas (2015-2017), where over 50 countries have reported local transmission (Ikejezie et al., 2017).

\section{Congenital Zika syndrome}

ZIKV infection in immune competent adults is often asymptomatic, although $20 \%$ of cases present with symptoms ranging from a mild, self-limiting febrile illness to more severe complications, including an association with Guillain-Barré syndrome and severe thrombocytopenia (Oehler et al., 2014; Parra et al., 2016; Sharp et al., 2016). ZIKV sparked a public health emergency because of increased incidence of microcephaly in Brazil in 2015, coincident with the emergence of ZIKV. Early studies in presumptively infected pregnant mothers revealed evidence of perinatal transmission and the presence of ZIKV in the amniotic fluid and fetal brain (Calvet et al., 2016; Driggers et al., 2016). In many cases, in utero ZIKV infection corresponded with profound fetal defects, including ocular abnormalities, brain calcifications, cerebral atrophy, microcephaly, and fetal loss (Brasil et al., 2016; de Paula Freitas et al., 2016; Driggers et al., 2016; Mlakar et al., 2016). Studies in non-human primate and animal models have supported a causal link between congenital ZIKV infection and the development of fetal abnormalities (Adams Waldorf et al., 2016; Cugola et al., 2016; Miner et al., 2016). Maternal ZIKV infection in mice results in intrauterine growth restriction, placental insufficiency, in utero viral transmission, increased cell death within the fetal brain, and fetal demise (Cugola et al., 2016; Miner et al., 2016). Whether fetal abnormalities are caused primarily from placental damage, direct effects of viral replication within the fetal brain, or a combination of both remains unclear. There are currently no specific therapeutics or vaccines approved for use in humans to combat or prevent ZIKV infection, although several promising pharmacological compounds and vaccines are currently under development (Durbin and Wilder-Smith, 2017; McArthur, 2017). In this review, we highlight the recent findings pertaining to immunity to ZIKV infection and discuss the host antiviral measures and countermeasures utilized by ZIKV to evade innate immune responses. 


\section{Immunity to ZIKV infection}

The initial events following ZIKV infection in humans are not well understood. Largely built on studies using DENV and WNV, it is believed that ZIKV likely infects keratinocytes, Langerhan cells, and dendritic cells as early targets of viral replication (Cerny et al., 2014; Lim et al., 2011). We have recently confirmed that human monocyte-derived Dendritic cells (DCs) support productive viral replication by both African and Asian lineage ZIKV viruses, however, the importance of human DCs during in vivo ZIKV infection remains unclear (Bowen et al., 2017). Through a limited analysis, ZIKV appears to induce systemic proinflammatory responses during human infection (Tappe et al., 2016). In particular, human ZIKV infection has correlated with leukopenia, characterized by monocytosis, thrombocytopenia, induction of pro-inflammatory cytokines (IL-1 $\beta$, IL-6, MIP1a), chemokines (IP-10 and RANTES) and cytokines that promote polyfunctional T cell responses (IL-2, IL-4, IL-9 and IL-17) (Tappe et al., 2016; Zammarchi et al., 2015). However, the cellular sources of inflammation during ZIKV infection are poorly understood. Human DCs do not secrete pro-inflammatory cytokines or type I IFN following ZIKV infection, suggesting that infected DCs may not be an important source of inflammatory cues during in vivo infection (Bowen et al., 2017). Although this study focused primarily on an in vitro infection model, it will be important to also understand the contribution of classical monocytes (CD14+CD16-), inflammatory monocytes (CD14+CD16+) and DCs, including both myeloid and plasmacytoid subsets, in promoting systemic inflammatory responses during human ZIKV infection.

ZIKV infection in a lung carcinoma epithelial cell line induces IFN $\beta$ secretion, while primary human skin fibroblasts up-regulate pro-inflammatory cytokine gene expression during ZIKV infection (Frumence et al., 2016; Hamel et al., 2015). Embryonic neuroprogenitor cells (NPCs) do not secrete pro-inflammatory cytokines following ZIKV infection (Hanners et al., 2016). Hofbauer cells, which are a placental macrophage recently identified as a reservoir of ZIKV behave in a similar manner and are poorly immunogenic during ZIKV infection (Bhatnagar et al., 2017; Quicke et al., 2016). In contrast, cranial neural crest cells secrete multiple cytokines involved in inflammation and neurogenesis at levels that promote apoptosis and pre-mature neuronal differentiation during ZIKV infection (Bayless et al., 2016). Combined, ZIKV infection can induce pro-inflammatory responses, but does so in a cell type specific manner. A better understanding of how inflammation is regulated within the placenta and the subsequent impact on the developing fetus will be critical to understanding ZIKV infection and pathogenesis.

ZIKV infection induces broadly neutralizing and protective humoral immune responses against both African and Asian lineage ZIKV strains (Dowd et al., 2016), suggesting a single ZIKV serotype. Interestingly, antibodies against DENV, and to a lesser extent WNV, cross-react with ZIKV but exhibit limited neutralization activity. Recent in vitro and in vivo studies suggest that these cross-reactive non-neutralizing antibodies may enhance infection through a phenomenon termed antibody dependent enhancement (ADE) (Andrade and Harris, 2017; Bardina et al., 2017; Priyamvada et al., 2016). In particular, passive transfer of DENV or WNV convalescent human serum at low treatment doses enhanced ZIKV infection and disease within a murine model, while higher treatment doses were protective (Bardina et 
al., 2017). Whether prior infection with DENV and WNV can similarly promote enhanced disease following secondary ZIKV challenge within the same host remains to be determined. The impact of cross-reactive antibodies on ZIKV pathogenesis within humans remains unclear, although it is plausible that these cross-reactive antibodies may provide a mechanism for ZIKV to cross the placenta through Fc receptor-mediated transcytosis. A better understanding of the in vivo relevance of ADE during ZIKV infection of an individual with prior flavivirus exposure, either through natural infection or vaccination, is of significant importance to current DENV and ZIKV vaccination efforts.

CD8+ T cell immunity appears to be important during ZIKV infection. In the acute phase, ZIKV-specific CD8+ T cells expand, are polyfunctional and exhibit in vivo cytotoxicity (Elong Ngono et al., 2017). In a non-human primate model of ZIKV infection using rhesus macaques, proliferating CD8+ T cells were observed by 6 days post-infection (dpi), peaked between 8-9 dpi, and had contracted by 14 dpi (Hirsch et al., 2017). Depletion of CD8+ T cells within a murine model compromises viral clearance from the periphery and central nervous system during ZIKV infection. Mice that genetically lack CD8+ T cells are also highly susceptible to ZIKV infection. Notably, CD8+ T cells isolated from ZIKV-infected mice promote viral clearance when adoptively transferred into naïve animals prior to ZIKV infection. Using a neonatal C57BL/6 model, CD8+ T cells have also been found to infiltrate into the CNS and may contribute to neurodegeneration (Manangeeswaran et al., 2016).

Recent work in a murine model suggests that DENV-specific CD8+ T cells can cross-react with ZIKV and promote viral clearance during ZIKV infection (Wen et al., 2017). The presence of protective, cross-reactive CD8+ T cell immunity has important implications for the development of $\mathrm{T}$ cell vaccines that may provide protection against multiple flaviviruses.

\section{Pattern recognition receptor control of ZIKV}

The Rentinoic acid inducible gene I (RIG-I)-like receptors (RLRs) family consists of the eponymous member RIG-I, as well as Melanoma differentiation antigen 5 (MDA5) and Laboratory of genetics and physiology 2 (LGP2). The RLRs are located within the cytoplasm of nearly every cell of the body and distinguish host from pathogen by recognizing unique structures found within viral RNA (Loo and Gale, 2011). RIG-I and MDA5 contain N-terminal caspase activation and recruitment domains (CARDs) that interact with the CARD located within the N-terminus of the central adaptor protein, mitochondrial antiviral signaling protein (MAVS) (Vazquez and Horner, 2015). LGP2 lacks CARDs and does not signal through MAVS, but instead functions as a regulator of RLR signaling (Quicke et al., 2017). RIG-I preferentially recognizes short dsRNA molecules, while MDA5 has a preference for longer dsRNA molecules (Kato et al., 2008). Upon ligand binding, RIG-I and MDA5 undergo conformation changes and post-translational modifications, including dephosphorylation and ubiquitination, which fully activate their ability to interact with MAVS (Gack et al., 2007; Wies et al., 2013). Upon interaction with RIG-I or MDA5, MAVS is thought to undergo CARD-dependent oligomerization, forming large MAVS aggregates that can, in vitro, potently activate downstream signaling (Hou et al., 2011). MAVS recruits members of the TNF receptor-associated factor (TRAF) family, E3 ubiquitin ligases that polyubiquitinate MAVS and promote the recruitment of NF-kappa-B essential modulator (NEMO), which itself recruits the serine/threonine protein kinases 
inhibitor of kappa-B kinase epsilon (IKKe) and TANK-binding kinase 1 (TBK1). IKKe and TBK1 phosphorylate and activate the latent transcription factors interferon regulatory factor-3 (IRF-3) and IRF-7, as well as nuclear factor kappa-B (NFkB), through phosphorylation and degradation of inhibitor of kappa-B (IKB). Upon nuclear translocation, IRF-3 promotes transcription of type I and III IFN and directly activates antiviral effector gene transcription, while NFrB promotes early type I IFN induction and drives proinflammatory cytokine production (Brownell et al., 2014; Daffis et al., 2007; Wang et al., 2010).

While the role of RLR signaling during ZIKV infection remains poorly understood, a few recent studies have shed light on their importance. Through the use of short interfering RNAs against the RLRs and TLRs in a human foreskin fibroblast cell line (HFF1 cells), Hamel and colleagues observed increased accumulation of ZIKV RNA in cells in which TLR3, RIG-I and MDA5, but not TLR7, gene expression was silenced as compared to control cells (Hamel et al., 2015). Within primary human DCs, RIG-I signaling potently restricted ZIKV replication, while IFN $\beta$ signaling was significantly less effective (Bowen et al., 2017). Despite observing blockade of type I IFN signaling, strong antiviral responses were observed during ZIKV infection in human DCs, including production of multiple antiviral effector molecules. This suggests that RLR signaling may play an essential role in inducing antiviral responses during ZIKV infection through a type I IFN-independent mechanism. In contrast, activation of RLR signaling by ZIKV during infection of neuroepithelial stem cells may result in mitotic arrest and apoptosis due to relocation of phosphorylated TBK1 from centrosomes to the mitochondria (Onorati et al., 2016). Together, this work suggests that while RLR signaling is likely protective during ZIKV infection, RLR activation may have unintended, negative consequences in dividing cells, such as stem cells. Future efforts will need to determine the cell intrinsic roles of RLR signaling during ZIKV infection, including the influence of RLR and other innate immune signaling pathways on the cell cycle of stem cells.

While little is known about the contributions of TLR3 signaling during ZIKV infection, a recent study argues for a potentially pathogenic role within NPCs (Dang et al., 2016). In this study, ZIKV replication within human cerebral organoid cultures was associated with decreased organoid size. Similar attenuated growth was also observed following treatment with poly(I:C), a non-specific agonist that can activate multiple PRRs, including TLR3, RIG-I, and MDA5 (Dang et al., 2016; Kato et al., 2008). Treatment of ZIKV-infected organoids with a specific TLR3 inhibitor partially reversed the growth attenuation. Combined, these findings suggest TLR3 signaling might play a pathogenic role in NPCs by promoting growth attenuation, potentially through regulation of pathways involved in apoptosis and neurogenesis. More rigorous study is needed to validate a role for TLR3 signaling in regulating neural progenitor growth and apoptosis, including the use of genetic ablation and in vivo studies.

\section{Type I and III IFN signaling and ZIKV countermeasures}

Type I IFN signaling establishes a robust antiviral state through induction of ISGs that restrict viral replication and spread within the host. Secreted IFN- $\alpha$ and IFN- $\beta$ bind to the 
IFN-a receptor (IFNAR) and promote phosphorylation of Janus kinase 1 (JAK1) and tyrosine kinase 2 (Tyk2), activating signal transduction and activator of transcription proteins 1 and 2 (STAT1/2). The STAT1/2 heterodimer will then associate with IRF-9, forming the IFN-stimulated gene factor 3 complex (ISGF3), and translocate to the nucleus to bind to specific sequences known as IFN stimulated response elements to drive production of antiviral effector genes (Schneider et al., 2014).

Type I and III IFNs can restrict ZIKV infection as demonstrated through in vitro and in vivo studies in both mice and primary human cells. The importance of type I IFN in mediating host restriction of ZIKV is evident through studies in murine models, which have consistently shown that immune competent adult mice do not support efficient ZIKV replication (Lazear et al., 2016). Antibody blockade of the type I IFN receptor enhances peripheral viral replication, however it is not sufficient to promote severe neuroinvasive disease. A genetic deficiency in type I IFN signaling shifts the balance to sustained viral replication and disseminated disease, promoting spread to the CNS and lethal infection (Lazear et al., 2016; Rossi et al., 2016). A combined deficiency in type I and II IFN, as well as a loss of STAT2 can also promote efficient viral replication, neuroinvasion, and lethality (Aliota et al., 2016; Rossi et al., 2016). Mice that are triply deficient in IRF-3, IRF-5, and IRF-7, and therefore produce minimal type I IFN, are also highly susceptible to lethal ZIKV infection (Lazear et al., 2016). Similar to related flaviviruses, multiple antiviral effector genes induced downstream of type I and III IFN signaling, including viperin and members of the IFITM family, have also been shown to have antiviral activity against ZIKV replication (Savidis et al., 2016; Van der Hoek et al., 2017). Type I IFN signaling is also important within primary human cells, where post-treatment of moDCs with IFN- $\beta$ inhibited ZIKV replication across African and Asian lineage strains, although the effect paled in comparison to treatment with a highly specific RIG-I agonist (Bowen et al., 2017).

In the context of the placenta, primary human syncytiotrophoblasts (STBs) are also resistant to ZIKV infection, contrasting with the permissiveness of human trophoblastic cell lines (Bayer et al., 2016). Constitutive secretion of the type III IFN, IFN $\lambda 1$, and to a lesser extent IFN $\lambda 2$, by STBs corresponds with their ability to restrict ZIKV replication. Treatment of permissive cells with conditioned media obtained from STBs also blocks ZIKV replication in a manner that partially depends on the activity of IFN $\lambda 1$ and IFN $\lambda 2$. In contrast, less differentiated trophoblastic cells, cytotrophoblasts (CTBs), support delayed and limited viral replication, and fail to secrete detectable IFN $\lambda 1$ secretion during ZIKV infection (Quicke et al., 2016; Tabata et al., 2016). This suggests that type III IFN may serve a protective role in restricting ZIKV replication within the placenta, but further study is needed to clarify potential cell type specific roles within the placenta.

ZIKV has developed several strategies to antagonize type I IFN signaling to evade the pressures of host innate immune responses. Recently, we demonstrated that human DCs, a target cell of mosquito-borne flaviviruses, are susceptible to productive viral replication across infection with African and Asian lineage ZIKV strains, yet these cells failed to produce detectable amounts of secreted type I or III IFN (Bowen et al., 2017). The defect was not due to a lack of activation of PRR signaling pathways as ZIKV-infected DCs strongly up-regulated transcripts for IFN- $\beta$, IFN- $\alpha$ and several antiviral genes (Bowen et al., 
2017; Kumar et al., 2016). Interestingly, we found that ZIKV appears to selectively inhibit translation of type I IFN proteins, while translation of other antiviral host proteins remained intact. This blockade in type I IFN protein translation appears to be a unique feature of ZIKV, as WNV and YFV do not seem to block translation or secretion of type I IFNs (Bowen and Suthar, data not shown). Interestingly, another study suggests that ZIKV nonstructural proteins may also inhibit type I IFN induction. Through over-expression studies, ZIKV NS1, NS4A, and NS5 were found to inhibit IRF3 and NF- $\times B$ signaling, although the precise mechanism is not yet clear (Kumar et al., 2016). Another study found that ZIKV NS1 and NS4B interact with TBK1 and impede activation of IRF3 (Wu et al., 2017). Combined, these studies demonstrate that ZIKV targets multiple points within the type I IFN induction signaling cascade.

ZIKV also counteracts type I IFN responses by antagonizing JAK/STAT signaling at multiple points. Recent work has demonstrated that ZIKV actively blocks STAT1 and STAT2 phosphorylation, a process that is critical for generation of the ISGF3 transcription factor complex and antiviral gene transcription (Bowen et al., 2017). However, the exact mechanism of this inhibition has yet to be determined. Similar to other mosquito-borne flaviviruses, Grant and colleagues observed that ZIKV targets human, but not murine, STAT2 for proteasome-dependent degradation (Grant et al., 2016b). Upon overexpression, the ZIKV NS5 protein, a critical component of viral RNA synthesis, interacts with human, but not murine STAT2 to promote its proteasomal degradation. While the mechanism of STAT2 degradation remains unclear, the host E3 ubiquitin ligase UBR4 is not involved, contrasting with the NS5 protein of the closely related DENV (Grant et al., 2016a; Kumar et al., 2016). Similar to DENV, the species specific degradation of STAT2 may explain the in vivo restriction of ZIKV in type I IFN-competent mice. In addition to NS5, overexpression of the ZIKV NS2B3 protein, particularly the helicase domain, also appeared to interfere with JAK/STAT signaling by interacting with JAK1 and targeting it for proteasomal degradation (Wu et al., 2017). As part of the arms race between virus and host, type I IFN signaling promoted the autophagic destruction of NS2B3 in a STAT1-dependent manner, thus limiting ZIKV replication. Despite these insights, the specific residues within ZIKV NS5 or NS2B3, as well as the importance of these viral proteins in the context of an intact virus remain unknown. Future studies that take advantage of the recently developed ZIKV infectious clones to generate viral mutants will be required to confirm the role of ZIKV viral proteins in antagonism of type I IFN signaling (Widman et al., 2017). Taken together, the ZIKV nonstructural proteins have been shown to inhibit the type I IFN signaling pathway at multiple points to promote viral replication.

\section{Summary}

Over the past year and a half, there have been over 2,500 publications on Zika virus (as determined by a search on PubMed.gov on 'Zika virus' with a publication range from 1/1/2016 to present). Much of the research efforts have focused on clinical case reports, development of animal models, development and testing vaccines in phase I clinical trials, identifying novel antivirals, dissecting ZIKV pathogenesis and uncovering virus-host interactions. While these studies have provided a significant advance in our understanding of the biology of ZIKV, there is a dearth of studies examining the human immune response to 
ZIKV infection. This insight is critical to appropriately advance our understanding of the immune parameters that contribute to protective immunity, as well as symptomatic outcome during ZIKV infection. Currently, much of our knowledge relies on animal models, some of which lack critical components of innate immune signaling or lack robustness in statistical measurements (non-human primate studies), and in vitro infection studies in primary and cultured cells. Future studies should focus on immune profiling of ZIKV-infected patients through a combination of cellular analysis and multi-omics based approaches. Several key outstanding questions still remain to be addressed and should be the focus of future research efforts: 1) What impact do cross-reactive antibodies play in flavivirus experienced individuals in promoting ZIKV infection? 2) How does ZIKV cross the placenta and infect the developing fetus? 3) What are the viral and host factors that contribute to ZIKV persistence in the placenta and other immune-privileged organs (e.g. eyes and testes)? Addressing these questions will provide much needed clarity and understanding for ZIKV pathogenesis and infection outcome. Furthermore, this will provide critical insight for rational development of vaccines that take into account the impact of cross-reactive antibodies and cellular responses in flavivirus-experienced individuals.

\section{Acknowledgments}

The Suthar laboratory is funded in part by National Institutes of Health grants U19AI083019, R56AI110516, R21AI113485, 2U19AI090023, U01AI131566, Emory University Department of Pediatrics Junior Faculty Focused Award, CCIV Pilot awards, Children's Healthcare of Atlanta, Emory Vaccine Center, and the Georgia Research Alliance.

\section{References}

Adams Waldorf KM, Stencel-Baerenwald JE, Kapur RP, Studholme C, Boldenow E, Vornhagen J, Baldessari A, Dighe MK, Thiel J, Merillat S, Armistead B, Tisoncik-Go J, Green RR, Davis MA, Dewey EC, Fairgrieve MR, Gatenby JC, Richards T, Garden GA, Diamond MS, Juul SE, Grant RF, Kuller L, Shaw DW, Ogle J, Gough GM, Lee W, English C, Hevner RF, Dobyns WB, Gale M Jr, Rajagopal L. Fetal brain lesions after subcutaneous inoculation of Zika virus in a pregnant nonhuman primate. Nat Med. 2016; 22(11):1256-1259. [PubMed: 27618651]

Aliota MT, Caine EA, Walker EC, Larkin KE, Camacho E, Osorio JE. Characterization of Lethal Zika Virus Infection in AG129 Mice. PLoS Negl Trop Dis. 2016; 10(4):e0004682. [PubMed: 27093158]

Andrade DV, Harris E. Recent advances in understanding the adaptive immune response to Zika virus and the effect of previous flavivirus exposure. Virus Res. 2017

Bardina SV, Bunduc P, Tripathi S, Duehr J, Frere JJ, Brown JA, Nachbagauer R, Foster GA, Krysztof D, Tortorella D, Stramer SL, Garcia-Sastre A, Krammer F, Lim JK. Enhancement of Zika virus pathogenesis by preexisting antiflavivirus immunity. Science. 2017; 356(6334):175-180. [PubMed: 28360135]

Bayer A, Lennemann NJ, Ouyang Y, Bramley JC, Morosky S, Marques ET Jr, Cherry S, Sadovsky Y, Coyne CB. Type III Interferons Produced by Human Placental Trophoblasts Confer Protection against Zika Virus Infection. Cell Host Microbe. 2016; 19(5):705-712. [PubMed: 27066743]

Bayless NL, Greenberg RS, Swigut T, Wysocka J, Blish CA. Zika Virus Infection Induces Cranial Neural Crest Cells to Produce Cytokines at Levels Detrimental for Neurogenesis. Cell Host Microbe. 2016; 20(4):423-428. [PubMed: 27693308]

Bhatnagar J, Rabeneck DB, Martines RB, Reagan-Steiner S, Ermias Y, Estetter LB, Suzuki T, Ritter J, Keating MK, Hale G, Gary J, Muehlenbachs A, Lambert A, Lanciotti R, Oduyebo T, MeaneyDelman D, Bolanos F, Saad EA, Shieh WJ, Zaki SR. Zika Virus RNA Replication and Persistence in Brain and Placental Tissue. Emerg Infect Dis. 2017; 23(3):405-414. [PubMed: 27959260] 
Bowen JR, Quicke KM, Maddur MS, O'Neal JT, McDonald CE, Fedorova NB, Puri V, Shabman RS, Pulendran B, Suthar MS. Zika Virus Antagonizes Type I Interferon Responses during Infection of Human Dendritic Cells. PLoS Pathog. 2017; 13(2):e1006164. [PubMed: 28152048]

Brasil P, Pereira JP Jr, Moreira ME, Ribeiro Nogueira RM, Damasceno L, Wakimoto M, Rabello RS, Valderramos SG, Halai UA, Salles TS, Zin AA, Horovitz D, Daltro P, Boechat M, Raja Gabaglia C, Carvalho de Sequeira P, Pilotto JH, Medialdea-Carrera R, Cotrim da Cunha D, Abreu de Carvalho LM, Pone M, Machado Siqueira A, Calvet GA, Rodrigues Baiao AE, Neves ES, Nassar de Carvalho PR, Hasue RH, Marschik PB, Einspieler C, Janzen C, Cherry JD, Bispo de Filippis AM, NielsenSaines K. Zika Virus Infection in Pregnant Women in Rio de Janeiro. N Engl J Med. 2016; 375(24): 2321-2334. [PubMed: 26943629]

Brownell J, Bruckner J, Wagoner J, Thomas E, Loo YM, Gale M Jr, Liang TJ, Polyak SJ. Direct, interferon-independent activation of the CXCL10 promoter by NF-kappaB and interferon regulatory factor 3 during hepatitis C virus infection. J Virol. 2014; 88(3):1582-1590. [PubMed: 24257594]

Calvet G, Aguiar RS, Melo AS, Sampaio SA, de Filippis I, Fabri A, Araujo ES, de Sequeira PC, de Mendonca MC, de Oliveira L, Tschoeke DA, Schrago CG, Thompson FL, Brasil P, Dos Santos FB, Nogueira RM, Tanuri A, de Filippis AM. Detection and sequencing of Zika virus from amniotic fluid of fetuses with microcephaly in Brazil: a case study. Lancet Infect Dis. 2016; 16(6): 653-660. [PubMed: 26897108]

Cerny D, Haniffa M, Shin A, Bigliardi P, Tan BK, Lee B, Poidinger M, Tan EY, Ginhoux F, Fink K. Selective susceptibility of human skin antigen presenting cells to productive dengue virus infection. PLoS Pathog. 2014; 10(12):e1004548. [PubMed: 25474532]

Cugola FR, Fernandes IR, Russo FB, Freitas BC, Dias JL, Guimaraes KP, Benazzato C, Almeida N, Pignatari GC, Romero S, Polonio CM, Cunha I, Freitas CL, Brandao WN, Rossato C, Andrade DG, Faria Dde P, Garcez AT, Buchpigel CA, Braconi CT, Mendes E, Sall AA, Zanotto PM, Peron JP, Muotri AR, Beltrao-Braga PC. The Brazilian Zika virus strain causes birth defects in experimental models. Nature. 2016; 534(7606):267-271. [PubMed: 27279226]

Daffis S, Samuel MA, Keller BC, Gale M Jr, Diamond MS. Cell-specific IRF-3 responses protect against West Nile virus infection by interferon-dependent and -independent mechanisms. PLoS Pathog. 2007; 3(7):e106. [PubMed: 17676997]

Dang J, Tiwari SK, Lichinchi G, Qin Y, Patil VS, Eroshkin AM, Rana TM. Zika Virus Depletes Neural Progenitors in Human Cerebral Organoids through Activation of the Innate Immune Receptor TLR3. Cell Stem Cell. 2016

de Paula Freitas B, de Oliveira Dias JR, Prazeres J, Sacramento GA, Ko AI, Maia M, Belfort R Jr. Ocular Findings in Infants With Microcephaly Associated With Presumed Zika Virus Congenital Infection in Salvador, Brazil. JAMA Ophthalmol. 2016

Dick GW, Kitchen SF, Haddow AJ. Zika virus. I. Isolations and serological specificity. Trans R Soc Trop Med Hyg. 1952; 46(5):509-520. [PubMed: 12995440]

Dowd KA, DeMaso CR, Pelc RS, Speer SD, Smith AR, Goo L, Platt DJ, Mascola JR, Graham BS, Mulligan MJ, Diamond MS, Ledgerwood JE, Pierson TC. Broadly Neutralizing Activity of Zika Virus-Immune Sera Identifies a Single Viral Serotype. Cell Rep. 2016; 16(6):1485-1491. [PubMed: 27481466]

Driggers RW, Ho CY, Korhonen EM, Kuivanen S, Jaaskelainen AJ, Smura T, Rosenberg A, Hill DA, DeBiasi RL, Vezina G, Timofeev J, Rodriguez FJ, Levanov L, Razak J, Iyengar P, Hennenfent A, Kennedy R, Lanciotti R, du Plessis A, Vapalahti O. Zika Virus Infection with Prolonged Maternal Viremia and Fetal Brain Abnormalities. N Engl J Med. 2016; 374(22):2142-2151. [PubMed: 27028667]

Durbin A, Wilder-Smith A. An update on Zika vaccine developments. Expert Rev Vaccines. 2017

Elong Ngono A, Vizcarra EA, Tang WW, Sheets N, Joo Y, Kim K, Gorman MJ, Diamond MS, Shresta S. Mapping and Role of the CD8+ T Cell Response During Primary Zika Virus Infection in Mice. Cell Host Microbe. 2017; 21(1):35-46. [PubMed: 28081442]

Frumence E, Roche M, Krejbich-Trotot P, El-Kalamouni C, Nativel B, Rondeau P, Misse D, Gadea G, Viranaicken W, Despres P. The South Pacific epidemic strain of Zika virus replicates efficiently in human epithelial A549 cells leading to IFN-beta production and apoptosis induction. Virology. 2016; 493:217-226. [PubMed: 27060565] 
Gack MU, Shin YC, Joo CH, Urano T, Liang C, Sun L, Takeuchi O, Akira S, Chen Z, Inoue S, Jung JU. TRIM25 RING-finger E3 ubiquitin ligase is essential for RIG-I-mediated antiviral activity. Nature. 2007; 446(7138):916-920. [PubMed: 17392790]

Grant A, Ponia SS, Tripathi S, Balasubramaniam V, Miorin L, Sourisseau M, Schwarz MC, SanchezSeco MP, Evans MJ, Best SM, Garcia-Sastre A. Zika Virus Targets Human STAT2 to Inhibit Type I Interferon Signaling. Cell Host Microbe. 2016a; 19(6):882-890. [PubMed: 27212660]

Grant A, Ponia SS, Tripathi S, Balasubramaniam V, Miorin L, Sourisseau M, Schwarz MC, SánchezSeco Mari P, Evans Matthew J, Best Sonja M, García-Sastre A. Zika Virus Targets Human STAT2 to Inhibit Type I Interferon Signaling. Cell Host \& Microbe. 2016b

Haddow AD, Schuh AJ, Yasuda CY, Kasper MR, Heang V, Huy R, Guzman H, Tesh RB, Weaver SC. Genetic characterization of Zika virus strains: geographic expansion of the Asian lineage. PLoS Negl Trop Dis. 2012; 6(2):e1477. [PubMed: 22389730]

Hamel R, Dejarnac O, Wichit S, Ekchariyawat P, Neyret A, Luplertlop N, Perera-Lecoin M, Surasombatpattana P, Talignani L, Thomas F, Cao-Lormeau VM, Choumet V, Briant L, Despres P, Amara A, Yssel H, Misse D. Biology of Zika Virus Infection in Human Skin Cells. J Virol. 2015; 89(17):8880-8896. [PubMed: 26085147]

Hanners NW, Eitson JL, Usui N, Richardson RB, Wexler EM, Konopka G, Schoggins JW. Western Zika Virus in Human Fetal Neural Progenitors Persists Long Term with Partial Cytopathic and Limited Immunogenic Effects. Cell Rep. 2016; 15(11):2315-2322. [PubMed: 27268504]

Hirsch AJ, Smith JL, Haese NN, Broeckel RM, Parkins CJ, Kreklywich C, DeFilippis VR, Denton M, Smith PP, Messer WB, Colgin LM, Ducore RM, Grigsby PL, Hennebold JD, Swanson T, Legasse AW, Axthelm MK, MacAllister R, Wiley CA, Nelson JA, Streblow DN. Zika Virus infection of rhesus macaques leads to viral persistence in multiple tissues. PLoS Pathog. 2017; 13(3):e1006219. [PubMed: 28278237]

Hou F, Sun L, Zheng H, Skaug B, Jiang QX, Chen ZJ. MAVS forms functional prion-like aggregates to activate and propagate antiviral innate immune response. Cell. 2011; 146(3):448-461. [PubMed: 21782231]

Ikejezie J, Shapiro CN, Kim J, Chiu M, Almiron M, Ugarte C, Espinal MA, Aldighieri S. Zika Virus Transmission - Region of the Americas, May 15, 2015-December 15, 2016. MMWR Morb Mortal Wkly Rep. 2017; 66(12):329-334. [PubMed: 28358795]

Kato H, Takeuchi O, Mikamo-Satoh E, Hirai R, Kawai T, Matsushita K, Hiiragi A, Dermody TS, Fujita T, Akira S. Length-dependent recognition of double-stranded ribonucleic acids by retinoic acid-inducible gene-I and melanoma differentiation-associated gene 5. J Exp Med. 2008; 205(7): 1601-1610. [PubMed: 18591409]

Kumar A, Hou S, Airo AM, Limonta D, Mancinelli V, Branton W, Power C, Hobman TC. Zika virus inhibits type-I interferon production and downstream signaling. EMBO Rep. 2016; 17(12):17661775. [PubMed: 27797853]

Lanciotti RS, Lambert AJ, Holodniy M, Saavedra S, Signor Ldel C. Phylogeny of Zika Virus in Western Hemisphere, 2015. Emerg Infect Dis. 2016; 22(5):933-935. [PubMed: 27088323]

Lazear HM, Govero J, Smith AM, Platt DJ, Fernandez E, Miner JJ, Diamond MS. A Mouse Model of Zika Virus Pathogenesis. Cell Host Microbe. 2016

Lim PY, Behr MJ, Chadwick CM, Shi PY, Bernard KA. Keratinocytes are cell targets of West Nile virus in vivo. J Virol. 2011; 85(10):5197-5201. [PubMed: 21367890]

Loo YM, Gale M Jr. Immune signaling by RIG-I-like receptors. Immunity. 2011; 34(5):680-692. [PubMed: 21616437]

Manangeeswaran M, Ireland DD, Verthelyi D. Zika (PRVABC59) Infection Is Associated with T cell Infiltration and Neurodegeneration in CNS of Immunocompetent Neonatal C57B1/6 Mice. PLoS Pathog. 2016; 12(11):e1006004. [PubMed: 27855206]

McArthur MA. Zika Virus: Recent Advances towards the Development of Vaccines and Therapeutics. Viruses. 2017; 9(6)

Miner JJ, Cao B, Govero J, Smith AM, Fernandez E, Cabrera OH, Garber C, Noll M, Klein RS, Noguchi KK, Mysorekar IU, Diamond MS. Zika Virus Infection during Pregnancy in Mice Causes Placental Damage and Fetal Demise. Cell. 2016; 165(5):1081-1091. [PubMed: 27180225] 
Mlakar J, Korva M, Tul N, Popovic M, Poljsak-Prijatelj M, Mraz J, Kolenc M, Resman Rus K, Vesnaver Vipotnik T, Fabjan Vodusek V, Vizjak A, Pizem J, Petrovec M, Avsic Zupanc T. Zika Virus Associated with Microcephaly. N Engl J Med. 2016; 374(10):951-958. [PubMed: 26862926]

Moore CA, Staples JE, Dobyns WB, Pessoa A, Ventura CV, Fonseca EB, Ribeiro EM, Ventura LO, Neto NN, Arena JF, Rasmussen SA. Characterizing the Pattern of Anomalies in Congenital Zika Syndrome for Pediatric Clinicians. JAMA Pediatr. 2017; 171(3):288-295. [PubMed: 27812690]

Oehler E, Watrin L, Larre P, Leparc-Goffart I, Lastere S, Valour F, Baudouin L, Mallet H, Musso D, Ghawche F. Zika virus infection complicated by Guillain-Barre syndrome--case report, French Polynesia, December 2013. Euro Surveill. 2014; 19(9)

Onorati M, Li Z, Liu F, Sousa AM, Nakagawa N, Li M, Dell'Anno MT, Gulden FO, Pochareddy S, Tebbenkamp AT, Han W, Pletikos M, Gao T, Zhu Y, Bichsel C, Varela L, Szigeti-Buck K, Lisgo S, Zhang Y, Testen A, Gao XB, Mlakar J, Popovic M, Flamand M, Strittmatter SM, Kaczmarek LK, Anton ES, Horvath TL, Lindenbach BD, Sestan N. Zika Virus Disrupts Phospho-TBK1 Localization and Mitosis in Human Neuroepithelial Stem Cells and Radial Glia. Cell Rep. 2016; 16(10):2576-2592. [PubMed: 27568284]

Parra B, Lizarazo J, Jimenez-Arango JA, Zea-Vera AF, Gonzalez-Manrique G, Vargas J, Angarita JA, Zuniga G, Lopez-Gonzalez R, Beltran CL, Rizcala KH, Morales MT, Pacheco O, Ospina ML, Kumar A, Cornblath DR, Munoz LS, Osorio L, Barreras P, Pardo CA. Guillain-Barre Syndrome Associated with Zika Virus Infection in Colombia. N Engl J Med. 2016; 375(16):1513-1523. [PubMed: 27705091]

Priyamvada L, Quicke KM, Hudson WH, Onlamoon N, Sewatanon J, Edupuganti S, Pattanapanyasat K, Chokephaibulkit K, Mulligan MJ, Wilson PC, Ahmed R, Suthar MS, Wrammert J. Human antibody responses after dengue virus infection are highly cross-reactive to Zika virus. Proceedings of the National Academy of Sciences of the United States of America. 2016; 113(28): 7852-7857. [PubMed: 27354515]

Quicke KM, Bowen JR, Johnson EL, McDonald CE, Ma H, O'Neal JT, Rajakumar A, Wrammert J, Rimawi BH, Pulendran B, Schinazi RF, Chakraborty R, Suthar MS. Zika Virus Infects Human Placental Macrophages. Cell Host Microbe. 2016; 20(1):83-90. [PubMed: 27247001]

Quicke KM, Diamond MS, Suthar MS. Negative regulators of the RIG-I-like receptor signaling pathway. Eur J Immunol. 2017; 47(4):615-628. [PubMed: 28295214]

Rossi SL, Tesh RB, Azar SR, Muruato AE, Hanley KA, Auguste AJ, Langsjoen RM, Paessler S, Vasilakis N, Weaver SC. Characterization of a Novel Murine Model to Study Zika Virus. Am J Trop Med Hyg. 2016

Savidis G, Perreira JM, Portmann JM, Meraner P, Guo Z, Green S, Brass AL. The IFITMs Inhibit Zika Virus Replication. Cell Rep. 2016; 15(11):2323-2330. [PubMed: 27268505]

Schneider WM, Chevillotte MD, Rice CM. Interferon-stimulated genes: a complex web of host defenses. Annu Rev Immunol. 2014; 32:513-545. [PubMed: 24555472]

Sharp TM, Munoz-Jordan J, Perez-Padilla J, Bello-Pagan MI, Rivera A, Pastula DM, Salinas JL, Martinez Mendez JH, Mendez M, Powers AM, Waterman S, Rivera-Garcia B. Zika Virus Infection Associated With Severe Thrombocytopenia. Clin Infect Dis. 2016; 63(9):1198-1201. [PubMed: 27418575]

Tabata T, Petitt M, Puerta-Guardo H, Michlmayr D, Wang C, Fang-Hoover J, Harris E, Pereira L. Zika Virus Targets Different Primary Human Placental Cells, Suggesting Two Routes for Vertical Transmission. Cell Host Microbe. 2016; 20(2):155-166. [PubMed: 27443522]

Tappe D, Perez-Giron JV, Zammarchi L, Rissland J, Ferreira DF, Jaenisch T, Gomez-Medina S, Gunther S, Bartoloni A, Munoz-Fontela C, Schmidt-Chanasit J. Cytokine kinetics of Zika virusinfected patients from acute to reconvalescent phase. Med Microbiol Immunol. 2016; 205(3):269273. [PubMed: 26702627]

Van der Hoek KH, Eyre NS, Shue B, Khantisitthiporn O, Glab-Ampi K, Carr JM, Gartner MJ, Jolly LA, Thomas PQ, Adikusuma F, Jankovic-Karasoulos T, Roberts CT, Helbig KJ, Beard MR. Viperin is an important host restriction factor in control of Zika virus infection. Sci Rep. 2017; 7(1):4475. [PubMed: 28667332]

Vazquez C, Horner SM. MAVS Coordination of Antiviral Innate Immunity. J Virol. 2015; 89(14): 6974-6977. [PubMed: 25948741] 
Wang J, Basagoudanavar SH, Wang X, Hopewell E, Albrecht R, Garcia-Sastre A, Balachandran S, Beg AA. NF-kappa B RelA subunit is crucial for early IFN-beta expression and resistance to RNA virus replication. J Immunol. 2010; 185(3):1720-1729. [PubMed: 20610653]

Weaver SC, Costa F, Garcia-Blanco MA, Ko AI, Ribeiro GS, Saade G, Shi PY, Vasilakis N. Zika Virus: History, Emergence, Biology, and Prospects for Control. Antiviral research. 2016

Wen J, Tang WW, Sheets N, Ellison J, Sette A, Kim K, Shresta S. Identification of Zika virus epitopes reveals immunodominant and protective roles for dengue virus cross-reactive CD8+ T cells. Nat Microbiol. 2017; 2:17036. [PubMed: 28288094]

Widman DG, Young E, Yount BL, Plante KS, Gallichotte EN, Carbaugh DL, Peck KM, Plante J, Swanstrom J, Heise MT, Lazear HM, Baric RS. A Reverse Genetics Platform That Spans the Zika Virus Family Tree. MBio. 2017; 8(2):16.

Wies E, Wang MK, Maharaj NP, Chen K, Zhou S, Finberg RW, Gack MU. Dephosphorylation of the RNA sensors RIG-I and MDA5 by the phosphatase PP1 is essential for innate immune signaling. Immunity. 2013; 38(3):437-449. [PubMed: 23499489]

Wu Y, Liu Q, Zhou J, Xie W, Chen C, Wang Z, Yang H, Cui J. Zika virus evades interferon-mediated antiviral response through the co-operation of multiple nonstructural proteins in vitro. Cell Discov. 2017; 3:17006. [PubMed: 28373913]

Zammarchi L, Stella G, Mantella A, Bartolozzi D, Tappe D, Gunther S, Oestereich L, Cadar D, Munoz-Fontela C, Bartoloni A, Schmidt-Chanasit J. Zika virus infections imported to Italy: clinical, immunological and virological findings, and public health implications. J Clin Virol. 2015; 63:32-35. [PubMed: 25600600] 


\section{Highlights}

- $\quad$ Zika virus (ZIKV) is a neurotropic mosquito-borne flavivirus of significant public health concern

- Humoral and cell-mediated responses correlate with protective immunity against ZIKV infection.

- $\quad$ Cross-reactive antibodies and CD8+T cell may influence ZIKV pathogenesis and infection outcome.

- $\quad$ ZIKV utilized a multifactorial process to antagonize the host type I IFN signaling pathway. 


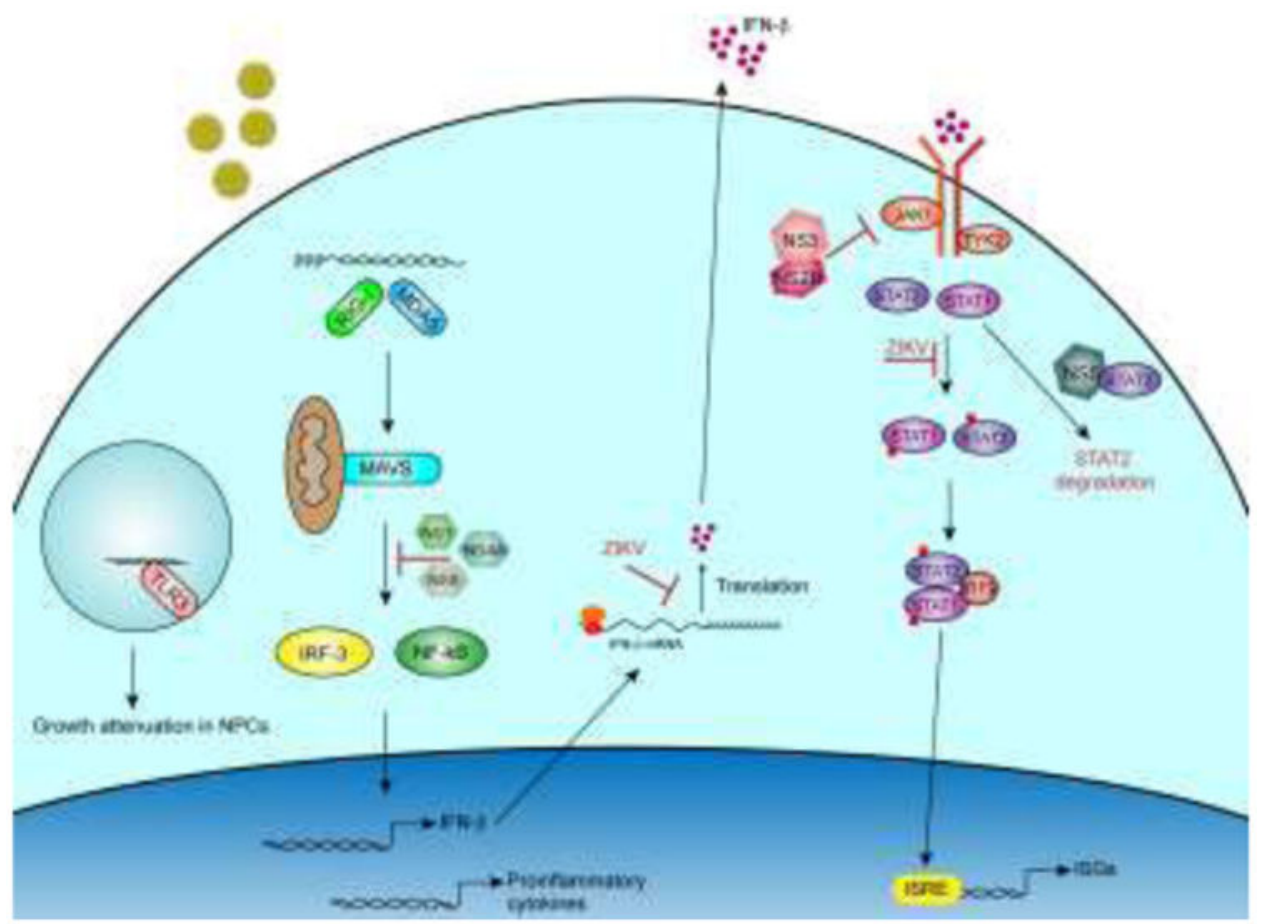

Figure 1. ZIKV antagonism of type I IFN signaling

RIG-I and MDA5 are thought to be the primary pattern recognition receptors that recognize ZIKV RNA in the cytoplasm. This leads to the activation of latent transcription factors, IRF-3 and NF-kB and subsequent transcription of IFN-b, proinflammatory cytokines and ISGs. Type I IFN is subsequently translated and secreted from the cell and binds to the type I IFN receptors. This leads to activation of JAK/STAT signaling and formation of the ISGF3 complex that enters the nucleus and binds to interferon-stimulated response elements and enhances expression of hundreds of ISGs. ZIKV proteins or processes within the type I IFN signaling cascade are noted. 